\title{
BMJ Open Risk of pyogenic liver abscess and endoscopic sphincterotomy: a population-based cohort study
}

\author{
Yen-Chun Peng, ${ }^{1,2}$ Cheng-Li Lin,, ${ }^{3,4}$ Fung-Chang Sung ${ }^{3,4}$
}

To cite: Peng Y-C, Lin C-L, Sung F-C. Risk of pyogenic liver abscess and endoscopic sphincterotomy: a populationbased cohort study. BMJ Open 2018;8:e018818. doi:10.1136/ bmjopen-2017-018818

- Prepublication history for this paper is available online. To view these files please visit the journal online (http://dx.doi.org/10.1136/ bmjopen-2017-018818).

Received 5 August 2017 Revised 8 February 2018 Accepted 9 February 2018
Check for updates

${ }^{1}$ Division of Gastroenterology, Department of Internal Medicine, Taichung Veterans General Hospital, Taichung, Taiwan ${ }^{2}$ School of Medicine, National Yang-Ming University, Taipei, Taiwan

${ }^{3}$ Management Office for Health Data, China Medical University Hospital, Taichung, Taiwan ${ }^{4}$ Graduate Institute of Clinical Medical Science and School of Medicine, College of Medicine, China Medical University, Taichung, Taiwan

Correspondence to Profosser Fung-Chang Sung; sungfc2016@gmail.com

\begin{abstract}
Objectives To evaluate the risk of pyogenic liver abscess (PLA) in patients receiving endoscopic sphincterotomy (ES). Setting A population-based cohort study using data from Taiwans' National Health Insurance Research Database was conducted. Patients aged 20 or older who had undergone an ES were considered as the ES cohort. The dates for the first hospitalisation of the patients receiving ES were defined as the index dates.

Participants Patients in the ES and non-ES cohorts were selected by $1: 1$ matching ratio based on a propensity score. A total of 8174 sex-matched, age-matched and index year-matched (1:1) pairs of patients receiving ES and 8174 patients without ES served as controls. Cox proportional hazards regression was employed to calculate the HRs and $95 \%$ Cls for the association between PLA and ES.

Results The overall incidence of PLA was significantly higher in the ES cohort than in the non-ES cohort (4.20 vs 0.94 , respectively, per 1000 person-year) with the adjusted HR (aHR) 4.50 (95\% Cl 3.38 to 6.58) A stratified analysis during the follow-up years revealed that when the ES cohort was compared with the non-ES cohort, they displayed a higher risk of PLA during the first follow-up year (aHR 4.35, 95\% Cl 2.26 to 8.39) which continued significantly over the next 4-5 years of follow-up. Conclusions Patients receiving ES are associated with having a higher risk of PLA.
\end{abstract}

\section{INTRODUCTION}

Endoscopic sphincterotomy (ES) is the most commonly used therapy for the treatment of common bile duct stones and is today considered to be a well-established standard of treatment for pancreatobiliary diseases. ${ }^{1-3}$ Standard ES involves the application of electrocautery to create an incision through the musculature of the biliary portion of the sphincter of Oddi and its use is considered as a safe, therapeutic procedure. ${ }^{45}$

Depending on the time frame after an ES, the complications resulting from an ES are both short term and long term. The percentage of short-term complications is estimated to be approximately $10 \%$, where procedural-related bleeding, perforation, pancreatitis and cardiopulmonary distress

\section{Strengths and limitations of this study}

- Endoscopic sphincterotomy is a procedure which eliminates the anatomic barrier of the biliary tract and intestine and is considered to be a well established, standard procedure for treating choledocholithiasis. There is no study that have direct link in the risk of pyogenic liver abscess in patients receiving an endoscopic sphincterotomy.

- Patients receiving endoscopic sphincterotomy are associated with having a higher risk of pyogenic liver abscess. The availability of these two large cohorts and follow-up conducted in pyogenic liver abscess risk after patients receiving endoscopic sphincterotomy.

- We used the code for only endoscopic sphincterotomy and the details of underlying diseases, which included mostly biliary, and pancreatic diseases are not clearly defined in the database.

are considered as the short-term complications. ${ }^{5}$ Long-term complications following an ES include stone recurrence, papillary stenosis and cholangitis, any of which may which occur in approximately $6 \%-24 \%$ of patients. $^{6-10}$

Pyogenic liver abscesses (PLA) are the most common type of human visceral abscess. The mechanism may be due to either the leakage of bowel contents or microbes which subsequently spread to the liver via the portal circulation or in the setting of a biliary infection. Risk factors for PLA include diabetes mellitus, underlying hepatobiliary or pancreatic disease, end-stage renal disease and the possible need for a liver transplant. ${ }^{11-13}$ Additionally, geographic and host associations should also be considered, such as Klebsiella pneumoniae which has been experienced in East Asia. ${ }^{14}$

Regarding the long-term follow-up after ES, most previous studies displayed recurrent biliary stones, cholangitis, stenosis and malignancy. ${ }^{7-10} 15-17$

ES creates a communication of bowel contents to both the biliary system and liver. 
Table 1 Comparisons in demographic characteristics and comorbidities between patients with and without endoscopic sphincterotomy

\begin{tabular}{|c|c|c|c|c|c|}
\hline & \multicolumn{4}{|c|}{ Endoscopic sphincterotomy } & \multirow{3}{*}{$\begin{array}{l}\text { Standard } \\
\text { difference }\end{array}$} \\
\hline & \multirow{2}{*}{$\begin{array}{l}\text { No } \\
(n=8174)\end{array}$} & & \multicolumn{2}{|l|}{ Yes } & \\
\hline & & & \multicolumn{2}{|c|}{$(n=8174)$} & \\
\hline & $\mathrm{n}$ & $\%$ & $\mathrm{n}$ & $\%$ & \\
\hline Age, mean $(\mathrm{SD}) \dagger$ & 68.5 & 14.6 & 66.9 & 15.0 & 0.11 \\
\hline \multicolumn{6}{|l|}{ Gender } \\
\hline Women & 3734 & 45.7 & 3832 & 46.9 & 0.02 \\
\hline Men & 4440 & 54.3 & 4342 & 53.1 & 0.02 \\
\hline \multicolumn{6}{|l|}{ Comorbidity } \\
\hline Congestive heart failure & 564 & 6.90 & 491 & 6.01 & 0.04 \\
\hline Biliary stone & 5695 & 69.7 & 5319 & 65.1 & 0.10 \\
\hline Cancer & 687 & 8.40 & 580 & 7.10 & 0.06 \\
\hline Hypertension & 3556 & 43.5 & 3186 & 39.0 & 0.09 \\
\hline $\begin{array}{l}\text { Chronic obstructive lung } \\
\text { disease }\end{array}$ & 855 & 10.5 & 714 & 8.74 & 0.06 \\
\hline Hyperlipidaemia & 1052 & 12.9 & 792 & 9.69 & 0.10 \\
\hline Alcoholic liver damage & 296 & 3.62 & 191 & 2.34 & 0.08 \\
\hline Cirrhosis & 561 & 6.86 & 455 & 5.57 & 0.05 \\
\hline Cholangitis & 793 & 9.70 & 1264 & 15.5 & 0.18 \\
\hline Cholecystitis & 663 & 8.11 & 602 & 7.36 & 0.03 \\
\hline Pancreatic diseases & 1544 & 18.9 & 1407 & 17.2 & 0.04 \\
\hline Chronic kidney disease & 795 & 9.73 & 657 & 8.04 & 0.06 \\
\hline Appendicitis & 167 & 2.04 & 152 & 1.86 & 0.01 \\
\hline Inflammatory bowel disease & 34 & 0.42 & 20 & 0.24 & 0.03 \\
\hline Diverticulosis & 215 & 2.63 & 206 & 2.52 & 0.01 \\
\hline
\end{tabular}

Thus, it is reasonable to consider that PLA is associated with ES. Up until now, there has been a lack of data associating the risk of PLA with ES.

To illuminate the risk of PLA and ES, we conducted a population based, cohort study to analyse the risk of PLA among patients receiving an ES.

\section{MATERIALS AND METHODS}

\section{Data source}

This was a longitudinal, cohort study using the National Health Institute Research Database (NHIRD) of the National Health Insurance (NHI) programme in Taiwan. The NHI programme began in 1995, and $99 \%$ of the 23.74 million Taiwan residents became covered. ${ }^{18}$ The details of the NHI programme and the NHIRD have been well documented in previous studies. ${ }^{16}{ }^{19}$ Diseases were coded in the NHIRD according to the 2001 International Classification of Diseases, Ninth revision, Clinical Modification (ICD-9-CM).

\section{Sampled participants}

Patients aged 20 or older who had undergone an ES (ICD-9-OP 51.84) were considered as the ES cohort. The dates for the first hospitalisation of the patients receiving ES were defined as the index dates. We excluded patients younger than 20 years, along with those having a history of PLA (ICD-9-CM code 572.0) before the index date, any PLA diagnosed within 1 year after the index date, a history of amoebic liver abscess (ICD-9-CM code 006.3) and/or those lacking information on their age and sex. The non-ES cohort was identified during the same period occurring from the years 2000-2010, with exclusion criteria similar to the ES cohort. Patients in the ES and non-ES cohorts were selected by a 1:1 matching ratio based on a propensity score. ${ }^{20}$ The propensity score was calculated using a logistic regression to estimate the probability of the disease assignment, based on the baseline variables, including year of ES diagnosis, age, gender and comorbidities of congestive heart failure (ICD-9-CM code 428), biliary stone (ICD-9-CM code 574), cancer (ICD-9-CM codes 140-208), hypertension (ICD-9-CM codes 401-405), chronic obstructive pulmonary disease (ICD-9-CM codes 491, 492, 496), hyperlipidaemia (ICD-9-CM code 272), alcoholic liver damage (ICD-9-CM code 571.0, 571.1 and 571.3), cirrhosis (ICD-9-CM codes 571.2, 571.5 and 571.6), cholangitis (ICD-9-CM code 


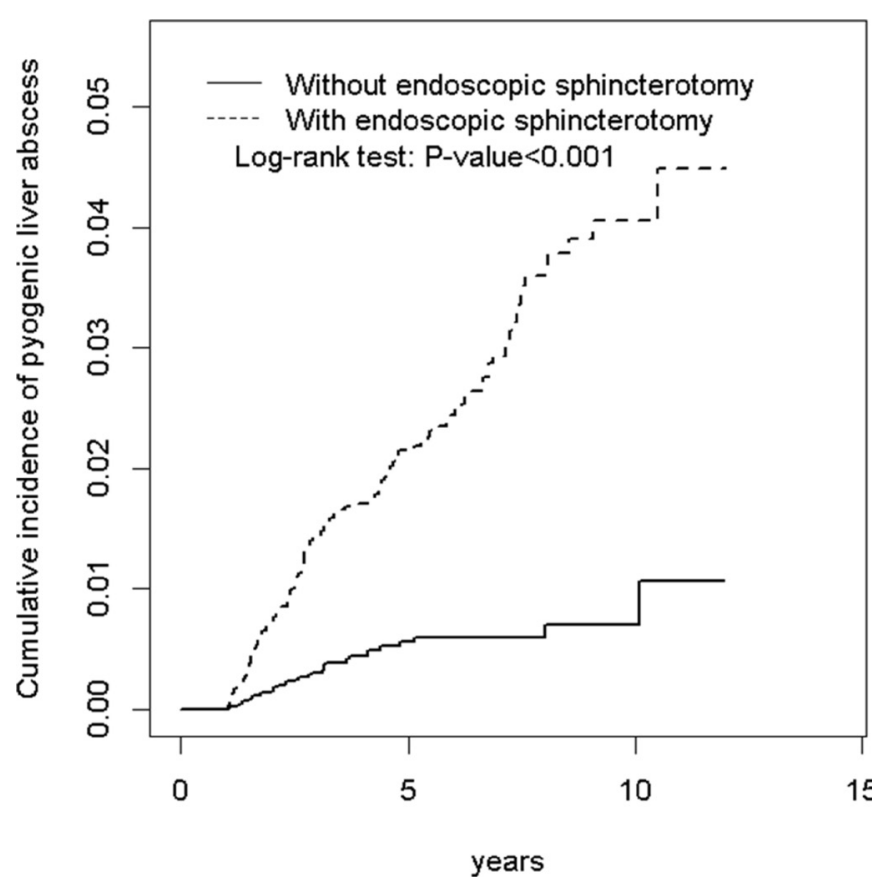

Figure 1 Kaplan-Meir method determined the cumulative incidence of pyogenic liver abscess compared between endoscopic sphincterotomy cohorts and comparisons without endoscopic sphincterotomy.

576.1), cholecystitis (ICD-9-CM code 575), pancreatic diseases (ICD-9-CM code 577), chronic kidney disease (ICD-9-CM codes 580-589), appendicitis (ICD-9-CM codes 540-543), inflammatory bowel disease (ICD-9-CM codes 555, 556) and diverticulosis (ICD-9-CM codes 562).

\section{Follow-up and outcome}

All the patients were monitored up until either a diagnosis of PLA was made, they were censored for withdrawal from the NHI programme, their death, or 31 December 2011, whichever occurred first.

\section{Statistical analysis}

Distributions in demographic variables, including age, gender and comorbidities were compared between the ES and non-ES cohorts. The baseline characteristics of the ES and non-ES cohorts were compared using standardised mean differences. ${ }^{21}$ A value of standardised mean differences equaled one or less, which indicates there was a negligible difference in means between ES and non-ES cohorts. Incidence density rates of PLA by gender, age and comorbidity were calculated in both cohorts. We assessed the cumulative incidence of PLA by using the Kaplan-Meier method in both the ES and non-ES cohorts, with significance based on the log-rank test. Univariable and multivariable Cox proportional hazard regressions were performed to measure the overall, gender, age, comorbidity, follow-up years risk of developing PLA. HRs and 95\% CIs were also estimated in the Cox model. The multivariate models were simultaneously adjusted for age, sex and the comorbidities of congestive heart failure, biliary stone, cancer, hypertension, chronic obstructive pulmonary disease, hyperlipidaemia, alcoholic liver damage, cirrhosis, cholangitis, cholecystitis, pancreatic diseases, chronic kidney disease, appendicitis, inflammatory bowel disease and diverticulosis. The entire matching procedure and all statistical

Table 2 Incidence and adjusted HR of pyogenic liver abscess stratified by sex, age and comorbidity compared patients with and without endoscopic sphincterotomy

\begin{tabular}{|c|c|c|c|c|c|c|c|c|}
\hline \multirow[b]{3}{*}{ All } & \multicolumn{6}{|c|}{ Endoscopic sphincterotomy } & \multirow[b]{3}{*}{$\begin{array}{l}\text { Crude HR } \\
(95 \% \mathrm{Cl})\end{array}$} & \multirow[b]{3}{*}{$\begin{array}{l}\text { Adjusted HR§ } \\
\text { (95\% Cl) }\end{array}$} \\
\hline & \multicolumn{3}{|l|}{ No } & \multicolumn{3}{|l|}{ Yes } & & \\
\hline & Event & $\begin{array}{l}\text { Person- } \\
\text { years }\end{array}$ & Rate† & Event & $\begin{array}{l}\text { Person- } \\
\text { years }\end{array}$ & Rate† & & \\
\hline & 33 & 35113 & 0.94 & 149 & 35454 & 4.20 & $4.50(3.08 \text { to } 6.56)^{\star \star \star}$ & \\
\hline \multicolumn{9}{|l|}{ Gender } \\
\hline \multicolumn{9}{|l|}{ Age } \\
\hline$\leq 49$ & 4 & 4928 & 0.81 & 23 & 5558 & 4.14 & $5.16(1.79 \text { to } 14.9)^{\star \star}$ & $7.30(2.42 \text { to } 22.0)^{\star \star \star}$ \\
\hline $50-64$ & 10 & 7762 & 1.29 & 38 & 8620 & 4.41 & $3.47(1.73 \text { to } 6.96)^{\star \star \star}$ & $3.30(1.63 \text { to } 6.69)^{\star * *}$ \\
\hline $65+$ & 19 & 22423 & 0.85 & 88 & 21276 & 4.14 & $4.90(2.99 \text { to } 8.05)^{\star \star \star}$ & $4.80(2.91 \text { to } 7.90)^{\star \star \star}$ \\
\hline \multicolumn{9}{|c|}{ Comorbidity } \\
\hline
\end{tabular}

${ }^{*} \mathrm{P}<0.05,{ }^{* \star} \mathrm{P}<0.01,{ }^{\star \star *} \mathrm{P}<0.001$.

†Incidence rate, per 1000 person-years.

†Relative HR.

$\S$ Adjusted HR, adjusted for age, sex and comorbidity of congestive heart failure, biliary stone, cancer, hypertension, chronic obstructive lung disease, hyperlipidaemia, alcoholic liver damage, cirrhosis, cholangitis, cholecystitis, pancreatic diseases, chronic kidney disease, appendicitis, inflammatory bowel disease and diverticulosis. 
Table 3 Trends of pyogenic liver abscess risks by stratified follow-up years

\begin{tabular}{|c|c|c|c|c|c|c|c|c|}
\hline \multirow[b]{3}{*}{$\begin{array}{l}\text { Follow-up } \\
\text { time, years }\end{array}$} & \multicolumn{6}{|c|}{ Endoscopic sphincterotomy } & \multirow[b]{3}{*}{ Crude HR $(95 \% \mathrm{Cl})$} & \multirow[b]{3}{*}{ Adjusted HR§ (95\% Cl) } \\
\hline & \multicolumn{3}{|l|}{ No } & \multicolumn{3}{|l|}{ Yes } & & \\
\hline & Event & $\begin{array}{l}\text { Person- } \\
\text { years }\end{array}$ & Rate† & Event & $\begin{array}{l}\text { Person- } \\
\text { years }\end{array}$ & Rate† & & \\
\hline $1-2$ & 11 & 15458 & 0.71 & 52 & 15319 & 3.39 & $4.81(2.51 \text { to } 9.23)^{\star \star \star}$ & $4.35(2.26 \text { to } 8.39)^{\star * *}$ \\
\hline $2-3$ & 15 & 9931 & 1.51 & 52 & 9785 & 5.31 & $3.54(1.99 \text { to } 6.28)^{\star \star \star}$ & $3.64(2.04 \text { to } 6.50)^{\star \star \star}$ \\
\hline
\end{tabular}

${ }^{*} \mathrm{P}<0.05,{ }^{* *} \mathrm{P}<0.01,{ }^{* * *} \mathrm{P}<0.001$.

†Incidence rate, per 1000 person-years.

fRelative HR.

$\S$ Adjusted HR, adjusted for age, sex and comorbidity of congestive heart failure, biliary stone, cancer, hypertension, chronic obstructive lung disease, hyperlipidaemia, alcoholic liver damage, cirrhosis, cholangitis, cholecystitis, pancreatic diseases, chronic kidney disease, appendicitis, inflammatory bowel disease and diverticulosis.

analyses were conducted using SAS V.9.4. A two-tailed $\mathrm{P}<0.05$ was considered significant.

\section{RESULTS}

\section{Characteristics of patients}

Our study cohort consisted of 8174 patients with ES and 8174 patients without ES. The mean age $( \pm \mathrm{SD})$ of the ES and non-ES cohorts was $66.9 \pm 15.0$ and $68.5 \pm 14.6$ years, respectively (table 1 ). Most patients were men (53.1\%). The major comorbidities were biliary stone $(65.1 \%$ vs $69.7 \%)$ and hypertension $(39.0 \%$ vs $43.5 \%)$ in these study cohorts, followed by pancreatic diseases $(17.2 \%$ vs $18.9 \%)$, cholangitis $(15.5 \%$ vs $9.70 \%)$ and hyperlipidaemia $(9.69 \%$ vs $12.9 \%)$. The average follow-up duration was $4.33 \pm 2.71$ years for the ES cohort and $4.30 \pm 2.60$ years for the non-ES cohort, respectively. Figure 1 shows that the cumulative incidence of PLA was higher in the ES cohort than that in the non-ES cohort by $3.33 \%$ at the end of the follow-up period (log-rank test $\mathrm{P}<0.001$ ).

\section{Incidence and adjusted HR of PLA after ES}

The overall incidence of PLA was significantly higher in the ES cohort than in the non-ES cohort (4.20 vs 0.94, respectively, per 1000 person-year) with the adjusted HR (aHR) 4.50 (95\% CI 3.38 to 6.58) (table 2). The ES cohort to the non-ES cohort aHR of PLA was significant for each status (including gender, age group and those with or without comorbidity).

\section{Trend of PLA risk by stratified follow-up years}

A stratified analysis of the follow-up years revealed that the ES cohort when compared with the non-ES cohort had higher risk of PLA during the first follow-up year (aHR $4.35,95 \%$ CI 2.26 to 8.39 ) and remained significantly so during 4-5 years of follow-up (aHR 4.59, 95\% CI 1.72 to 12.2). The risk of PLA remained even beyond 5 years of follow-up (aHR 12.1, 95\% CI 2.80 to 52.2) (table 3).

\section{Risk of pyogenic liver abscess by ES and cholangitis}

Table 4 outlines the interaction effects of ES and cholangitis towards the risk of PLA. Relative to the non-ES cohort without cholangitis, the patients receiving ES with cholangitis were at a much higher risk of PLA (aHR 6.64, 95\% CI 3.82 to 11.5 ), when compared with patients with only cholangitis (aHR 3.77, 95\% CI 1.69 to 8.41 ) or with only ES (aHR 5.48, 95\% CI 3.56 to 8.44) (table 4, the P value of interaction $=0.03$ ).

\section{DISCUSSION}

The association between PLA and ES is demonstrated by our results, which show that patients receiving ES have higher incidence rates of PLA than those in the

Table 4 Cox proportional hazard regression analysis for the risk of pyogenic liver abscess by endoscopic sphincterotomy and cholangitis

\begin{tabular}{llrrrll}
\hline Variables & & Event & Person-years & Rate† & Adjusted HR¥ (95\% Cl) & P value \\
\hline Endoscopic sphincterotomy & Cholangitis & & & & & 0.03 \\
No & No & 25 & 32177 & 0.78 & 1 (reference) & \\
No & Yes & 8 & 2936 & 2.72 & $3.77(1.69 \text { to } 8.41)^{\star \star}$ & \\
Yes & No & 122 & 30378 & 4.02 & $5.48(3.56 \text { to } 8.44)^{\star \star \star}$ & \\
Yes & Yes & 27 & 5076 & 5.32 & $6.64(3.82 \text { to } 11.5)^{\star \star \star}$ & \\
\hline
\end{tabular}

${ }^{*} \mathrm{P}<0.05,{ }^{* *} \mathrm{P}<0.01,{ }^{* * *} \mathrm{P}<0.001$

†Per 1000 person-year.

$\ddagger$ Model was adjusted for age, sex and other comorbidities. 
control group (4.02 vs 0.94 cases per 1000 person-years, $\mathrm{P}<0.001)$. The adjusted HR for PLA was found to be 4.50 (95\% CI 3.08 to 6.58) for patients receiving ES, after adjusting for age, sex and any possible comorbidities. The risk becomes even more significant when the follow-up years exceed five (adjust HR 12.1, 95\% CI 2.80 to 52.2). Thus, PLA would be considered as one of the events which is associated with ES during long-term follow-up. ES experience is also considered to be one of the risks of PLA.

There is no clearly set time for the duration of follow-up when discussing the long-term complications of ES. A hospital-based study regarding endoscopic retreatment for biliary stones after ES is defined to be 5 years, and then a follow-up choledochal conditions due to increased risk of complications is suggested. ${ }^{22}$ According to our results, PLA risk was determined to occur within 1 year after ES and could be found to be increasing even more than that during the 5-year span. Thus, PLA risk would be needed to be carefully monitored throughout follow-up. Risk of PLA was found to be more significant in non-comorbidity and young-aged patients. We could explain that elderly patients and those experiencing comorbidity carry a higher risk of PLA.

After decades of development, ES is still considered to be the requisite standard of care and therefore has become the most commonly used procedure for the endoscopic treatment of biliary diseases, including choledocholithiasis. ES is applied to cut the biliary sphincter in order to eliminate the principal anatomic barrier impeding stone passage and facilitate biliary manipulation. On reviewing available literature, long-term choledochal complications after ES include recurrent cholangitis, choledocholithiasis, biliary stenosis and cholecystitis. ${ }^{6-1017}$ After ES, the anatomic barrier of the hepatobiliary system and intestine is removed, resulting in the communication causing an ascending migration of the bowel contents. The ascending movement would not be limited to strictly the biliary system only. Intrahepatic biliary system and even in hepatic canaliculi would be involved. Patients experiencing ES would remain under the risk of PLA.

There seemed to be no large survey for PLA after ES except for case reports. ${ }^{23}{ }^{24}$ Taneka et al report about five PLA in 419 patients receiving ES in a long-term follow-up for ES study. ${ }^{25}$ Interestingly, a smaller study about PLA demonstrated that patients with ES is good prognostic factor associated resolution within 6 weeks. ${ }^{26}$ Based on the communicating with intestine, risk of PLA were also found in patients receiving pancreaticoduodenostomy and hepatojejunostomy. ${ }^{27} 28$

PLA has become a worldwide health problem that is not limited to only Taiwan. When focusing on the risks of PLA, diabetes, end-stage renal disease, hepatobiliary diseases, pancreatic diseases and the need for a liver transplant are all considered risk factors. ${ }^{11-13}{ }^{29-31}$ Biliary disease is also considered as a risk of PLA, but there is lack of mention to ES. ${ }^{32}$ Based on our results, patients receiving ES would also be considered to be a risk of PLA.
In the study, we first defined the association between ES and PLA and recognised ES as a definite risk factor for PLA. There are, however, several limitations for the present study. First, we used the code for only ES, and any underlying diseases, which included mostly biliary and pancreatic diseases. However, we did adjust both biliary and pancreatic disease, as shown in table 1 . Second, the follow-up duration is around 4.3 years, with the longest set at about 7 years, due to the limitations of the database. We would expect to see a more significant PLA risk appearing under a longer follow-up period.

Our results demonstrate a significant risk of PLA during follow-up periods for patients receiving ES. Further investigations, including bacterial culture, details of biliary systems and the analysis of clinical data, would be valuable studies that could be performed under a hospital-based inquiry.

Contributors Y-CP, C-LL and F-CS were involved in the conception and design, collection and assembly of data and data analysis and interpretation. Y-CP supported the administration. All authors contributed to the manuscript writing and revision and final approval of the manuscript.

Funding This work was supported by grants from the Ministry of Health and Welfare, Taiwan(MOHW107-TDU-B-212-123004), China Medical University Hospital, Academia Sinica Stroke Biosignature Project (BM10701010021), MOST Clinical Trial Consortium for Stroke (MOST 106-2321-B-039-005-). Tseng-Lien Lin Foundation, Taichung, Taiwan, and Katsuzo and Kiyo Aoshima Memorial Funds, Japan.

Competing interests None declared.

Patient consent Not required.

Ethics approval Institutional Review Board (IRB) of China Medical University and Hospital in Taiwan (CMUH104-REC2-115).

Provenance and peer review Not commissioned; externally peer reviewed.

Data sharing statement The Ministry of Health and Welfare must approve our application to access this data. Any researcher interested in accessing this dataset can submit an application form to the Ministry of Health and Welfare requesting access. Please contact the staff of MOHW (email: stcarolwu@mohw.gov.tw) for further assistance. Taiwan Ministry of Health and Welfare Address: No. 488, Sec. 6, Zhongxiao E. Rd., Nangang Dist., Taipei City 115, Taiwan (ROC). Phone: +886-28590-6848. All relevant data are within the paper.

Open Access This is an Open Access article distributed in accordance with the Creative Commons Attribution Non Commercial (CC BY-NC 4.0) license, which permits others to distribute, remix, adapt, build upon this work non-commercially, and license their derivative works on different terms, provided the original work is properly cited and the use is non-commercial. See: http://creativecommons.org/ licenses/by-nc/4.0/

(c) Article author(s) (or their employer(s) unless otherwise stated in the text of the article) 2018. All rights reserved. No commercial use is permitted unless otherwise expressly granted.

\section{REFERENCES}

1. Dumonceau JM, Delhaye M, Tringali A, et al. Endoscopic treatment of chronic pancreatitis: European Society of Gastrointestinal Endoscopy (ESGE) clinical guideline. Endoscopy 2012;44:784-800.

2. Maple JT, Ben-Menachem T, Anderson MA, et al. The role of endoscopy in the evaluation of suspected choledocholithiasis. Gastrointest Endosc 2010;71:1-9.

3. Williams EJ, Green J, Beckingham I, et al. Guidelines on the management of common bile duct stones (CBDS). Gut 2008;57:1004-21.

4. Binmoeller KF, Schafer TW. Endoscopic management of bile duct stones. J Clin Gastroenterol 2001;32:106-18.

5. Freeman ML, Nelson DB, Sherman S, et al. Complications of endoscopic biliary sphincterotomy. N Engl J Med 1996;335:909-19.

6. Hawes RH, Cotton PB, Vallon AG. Follow-up 6 to 11 years after duodenoscopic sphincterotomy for stones in patients with prior cholecystectomy. Gastroenterology 1990;98:1008-12. 
7. Wojtun S, Gil J, Gietka W, et al. Endoscopic sphincterotomy for choledocholithiasis: a prospective single-center study on the shortterm and long-term treatment results in 483 patients. Endoscopy 1997;29:258-65.

8. Yasuda I, Fujita N, Maguchi H, et al. Long-term outcomes after endoscopic sphincterotomy versus endoscopic papillary balloon dilation for bile duct stones. Gastrointest Endosc 2010;72:1185-91.

9. Sugiyama M, Suzuki Y, Abe N, et al. Endoscopic retreatment of recurrent choledocholithiasis after sphincterotomy. Gut 2004:53:1856-9.

10. Sugiyama M, Atomi Y. Follow-up of more than 10 years after endoscopic sphincterotomy for choledocholithiasis in young patients. Br J Surg 1998;85:917-21.

11. Mohsen AH, Green ST, Read RC, et al. Liver abscess in adults: ten years experience in a UK centre. QJM 2002;95:797-802.

12. Thomsen RW, Jepsen P, Sørensen HT. Diabetes mellitus and pyogenic liver abscess: risk and prognosis. Clin Infect Dis 2007;44:1194-201.

13. Tsai LW, Chao PW, Ou SM, Sm O, et al. Pyogenic liver abscess in end-stage renal disease patients: a nationwide longitudinal study. Hemodial Int 2015;19:72-9.

14. Tsai FC, Huang YT, Chang LY, et al. Pyogenic liver abscess as endemic disease, Taiwan. Emerg Infect Dis 2008;14:1592-600.

15. Kalaitzis J, Vezakis A, Fragulidis G, et al. Effects of endoscopic sphincterotomy on biliary epithelium: a case-control study. World $J$ Gastroenterol 2012;18:794-9.

16. Peng YC, Lin CL, Hsu WY, et al. Association of endoscopic sphincterotomy or papillary balloon dilatation and biliary cancer: a population-based cohort study. Medicine 2015;94:e926.

17. Sugiyama M, Atomi $Y$. Risk factors predictive of late complications after endoscopic sphincterotomy for bile duct stones: longterm (more than 10 years) follow-up study. Am J Gastroenterol 2002;97:2763-7.

18. Database NHIR. Taiwan. 2015 http://nhird.nhri.org.tw/en/index.html.

19. Wang CC, Chang CT, Lin CL, et al. Spinal cord injury is associated with an increased risk of atrial fibrillation: a population-based cohort study. Heart Rhythm 2016;13:416-23.

20. Parsons LS, Ovation Research Group. Performing a 1:N casecontrol match on propensity score. Seattle, Washington: SUGI 29, 2004:165-29.
21. Austin PC. Balance diagnostics for comparing the distribution of baseline covariates between treatment groups in propensity-score matched samples. Stat Med 2009;28:3083-107.

22. Keizman D, Shalom MI, Konikoff FM. An angulated common bile duct predisposes to recurrent symptomatic bile duct stones after endoscopic stone extraction. Surg Endosc 2006;20:1594-9.

23. Correa Bonito A, Mora-Guzmán I, García-Sanz I, et al. Liver abscess after endoscopic retrograde cholangiopancreatography with presence of Actinomyces naeslundii. Cir Esp 2017:95:51-2.

24. Gavini S, Kadiyala S, Venkatarami Reddy V, et al. Large liver abscess after ERCP and laparoscopic cholecystectomy. HPB 2016;18:e315-e316.

25. Tanaka M, Takahata S, Konomi $\mathrm{H}$, et al. Long-term consequence of endoscopic sphincterotomy for bile duct stones. Gastrointest Endosc 1998;48:465-9.

26. Wong WM, Wong BC, Hui CK, et al. Pyogenic liver abscess: retrospective analysis of 80 cases over a 10-year period. J Gastroenterol Hepatol 2002;17:1001-7.

27. Njoku VC, Howard TJ, Shen C, et al. Pyogenic liver abscess following pancreaticoduodenectomy: risk factors, treatment, and long-term outcome. J Gastrointest Surg 2014;18:922-8.

28. Röthlin MA, Löpfe M, Schlumpf R, et al. Long-term results of hepaticojejunostomy for benign lesions of the bile ducts. Am J Surg 1998;175:22-6.

29. Chan KS, Chen CM, Cheng KC, et al. Pyogenic liver abscess: a retrospective analysis of 107 patients during a 3-year period. Jpn J Infect Dis 2005;58:366-8.

30. Kang SC, Hwang SJ. Impact of advanced age on inpatients with pyogenic liver abscess in Taiwan: a nationwide claim-based analysis. $J$ Chin Med Assoc 2011;74:539-43.

31. Tian LT, Yao K, Zhang XY, et al. Liver abscesses in adult patients with and without diabetes mellitus: an analysis of the clinical characteristics, features of the causative pathogens, outcomes and predictors of fatality: a report based on a large population, retrospective study in China. Clin Microbiol Infect 2012;18:E314-E330.

32. Cheng HC, Chang WL, Chen WY, et al. Long-term outcome of pyogenic liver abscess: factors related with abscess recurrence. J Clin Gastroenterol 2008;42:1110-5. 